Journal of Engineering Sciences, Assiut University, Vol. 40, No. 3, pp.723 -730, May 2012

\title{
EXPERIMENTS AND CALCULATIONS OF THE ROOM TEMPERATURE AFFECTED BY A DIRECT EVAPORATIVE COOLER DURING HOT AND DRY CLIMATE
}

\begin{abstract}
Waleed A. Abdel-Fadeel' and Soubhi A. Hassanein ${ }^{2}$
${ }^{1,2}$ Assistant Professor, Department of Mechanical Engineering, Aswan

Faculty of Energy Engineering, South Valley University, Egypt

${ }^{2}$ Corresponding author. Tel: +20 141480210, Fax: +20 973481235 ,

E-mail address: soubhi_a@yahoo.com, P. O.:81528 Aswan, Egypt

(Received December 10, 2011 Accepted March 14, 2012)

Direct evaporative coolers are widely used in very hot and dry climate such as Aswan city. The accepted reduction of temperature and the value of relative humidity inside the buildings is an interesting topic. Experiments were made to measure the reduction of the room temperature due to the cooled air exiting from a direct evaporative cooler. All experiments are made during an ambient relative humidity less than $20 \%$ and the room was maintained at the same volume and heat load. The instant room temperatures were measured during the time until the steady state at different flow rates of cooled air and different very hot ambient temperatures. The experimental results were used to determine an empirical equation capable to predict the reduction of the room temperature at different ambient temperatures during very dry climate.
\end{abstract}

KEYWORDS: Hot and Dry climate; Evaporative system; Air cooler; Experimentation; Calculation.

\begin{tabular}{|cllll|}
\hline \multicolumn{4}{|c|}{ NOMENCLATURE } \\
$g$ & gravitational acceleration $\left(\mathrm{m} / \mathrm{s}^{2}\right)$ & $T_{i}$ & initial room temperature $\left({ }^{\circ} \mathrm{C}\right)$ \\
$Q$ & volume flow of cooled air $\left(\mathrm{m}^{3} / \mathrm{s}\right)$ & $T_{w}$ & wet bulb temperature $\left({ }^{\circ} \mathrm{C}\right)$ \\
$R H$ & ambient relative humidity $(\%)$ & $V$ & room volume $\left(\mathrm{m}^{3}\right)$ \\
$T$ & instant room temperature $\left({ }^{\circ} \mathrm{C}\right)$ & Greek \\
$T_{a}$ & ambient temperature $\left({ }^{\circ} \mathrm{C}\right)$ & $\varepsilon$ & cooler effectiveness $\%$ \\
$T_{e}$ & air temperature at exit from cooler & $\Delta T$ & maximum reduction of room \\
& $\left({ }^{\circ} \mathrm{C}\right)$ & & temperature $\left(\mathrm{T}_{\mathrm{i}}-\mathrm{T}_{\mathrm{f}}\right)\left({ }^{\circ} \mathrm{C}\right)$ \\
$T_{f}$ & final room temperature $\left({ }^{\circ} \mathrm{C}\right)$ & & non-dimensional group $\left(\frac{g V^{5 / 3}}{Q^{2}}\right)$ \\
& & $\phi$ & \\
\hline
\end{tabular}

\section{INTRODUCTION}

Aswan is one of the cities well known for its hot and dry climates. The temperature in summer exceeds $35{ }^{\circ} \mathrm{C}$ with relative humidity (RH) less than $20 \%$. In recent years, the direct evaporative cooler has been introduced because of low energy consumption and easy maintenance. The evaporative cooling system is more efficient in places where the climate is hot and dry. Many factors affect the reduction of room temperature such 
as ambient temperature, ambient relative humidity, flow rate of cooled air, room volume, cooler effectiveness, and heat load. The effect of ambient temperature and flow rate of cooled air are studied in this paper. The Evaporative cooling process is an adiabatic humidification that does not involve heat loss or gain. Sensible heat from the air evaporates the water that contacts the fresh air. The sensible heat converts into latent heat, which decreases the dry bulb temperature and increases both the relative humidity and water vapor content of the air. The airflow is totally renewed from outside across the evaporative cooler. Lertsatitthanakorn et al. [1] investigated the feasibility of using direct evaporative cooling to improve the indoor air conditions in a silkworm rearing house. They measured the hourly variation of room temperature and humidity during hot climate. Most studies on evaporative cooling focused on the experimental and theoretical overall performances of the evaporative cooling systems. Recently theoretical and numerical studies on the process of evaporative cooling systems were introduced by Fouda and Melikyan [2], Chen et al. [3], Riangvilaikul and Kumar [4], Wu et al. [5,6], Lazzarin [7], Qureshi and Zubair [8,9], Camargo et al. [10], Anyanwu [11], and Kumar and Mullick [12].

\section{EXPERIMENTAL WORK}

Experiments were made during the month of June/2010. The ambient temperature was in the range of $30-46{ }^{\circ} \mathrm{C}$ and the relative humidity was less than $20 \%$. The evaporative cooler was installed in an empty and closed reinforced concrete room of 5.7 x 3.7 x 3.3 $\mathrm{m}^{3}$ as shown in figure 1 . The source of the heat was solar radiation from the sun, beating down on the roof and walls, and pouring through one south glass window $(1 \mathrm{x}$ $1 \mathrm{~m}^{2}$ ). All walls were shaded while the ceiling was exposed to the sun. The cooled air, which comes from cooler, was delivered into the room at seven different flow rates Q. The test rig was instrumented to measure both air temperature and velocity, using digital air velocity and temperature instrument as shown in Figure 2. It has the capability to be connected to a computer and/or a printer for accessing data and printing it. The specifications of the air velocity and temperature meter are listed in Table 1.

The velocity profile of cooled air was determined at the cooler exit and the mean velocity was calculated. By using the mean velocity and the exit cooler area, the flow rate of cooled air was calculated. Measurements were made at very high ambient temperatures of 36,42 and $45{ }^{\circ} \mathrm{C}$. The average temperature inside the room was measured with the time until the steady state was reached. Cooler effectiveness $\varepsilon$ was calculated at every experiment according to the following equation.

Table 1 Specification of the motive air Thermo-Anemoter air meter unit.

\begin{tabular}{|lll|}
\hline Measured quantity & Velocity & Temperature \\
Range & $0.2-25 \mathrm{~m} / \mathrm{sec}$ & -20 to $60{ }^{\circ} \mathrm{C}$ \\
Accuracy & $( \pm 2 \%+0.2)$ & $\pm 0.8{ }^{\circ} \mathrm{C}$ \\
Resolution & $0.1 \mathrm{~m} / \mathrm{sec}$ & $0.1^{\circ} \mathrm{C}$ \\
\hline
\end{tabular}

$\varepsilon=\frac{\mathrm{T}_{\mathrm{a}}-\mathrm{T}_{\mathrm{e}}}{\mathrm{T}_{\mathrm{a}}-\mathrm{T}_{\mathrm{w}}} \times 100$ 


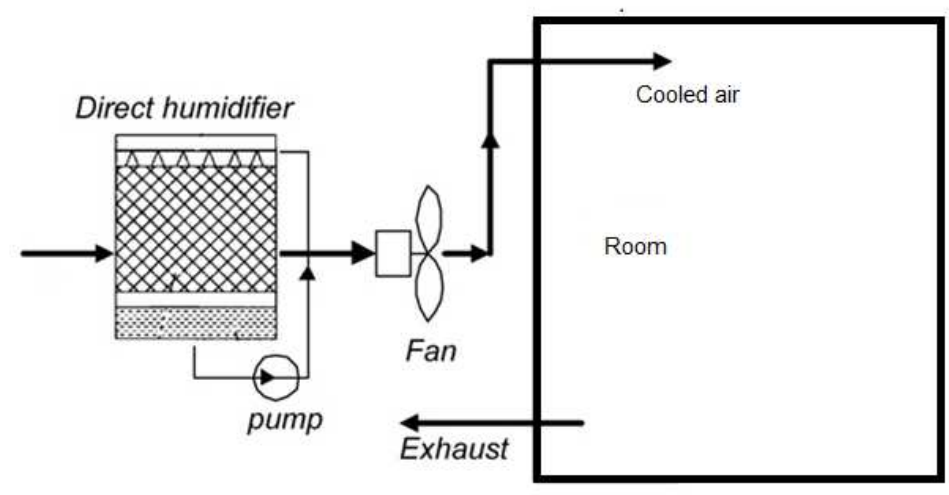

Figure 1 scheme of evaporative cooling air conditioning system

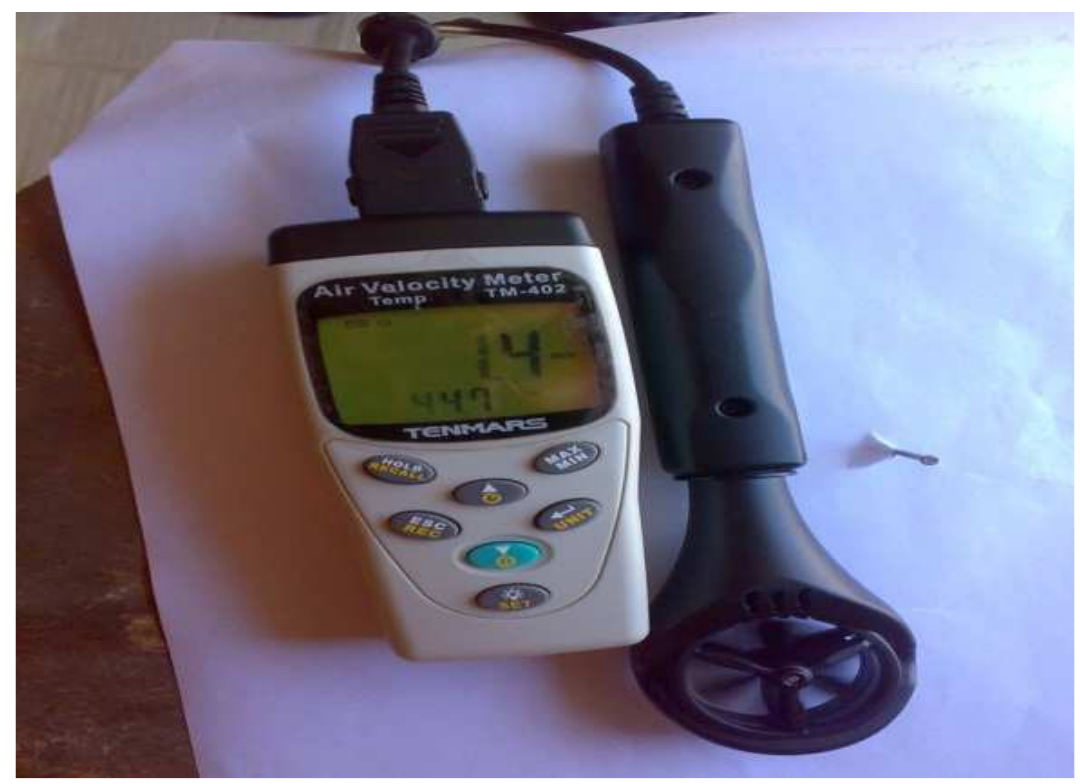

Figure 2 Digital air velocity and temperature instrument

It was approximately constant in the range of $75-78 \%$. The measured relative humidity inside the room increased with the time and did not exceed $60 \%$ at the steady state.

Figures 3, 4 and 5 show the reduction of the initial room temperature with the time at different flow rates of cooled air and ambient temperatures.

At the same ambient temperature, the reduction of the initial room temperature is increasing with the increase in flow rate of cooled air.

For the same flow rate of cooled air, the reduction of the initial room temperature is decreasing with the increase in the ambient temperature. The reduction of the room temperature was high in the first hour while it tends to be constant in the next half hour. In the last half hour, the reduction of the room temperature was constant. 
Figure 6 shows the maximum reduction of the initial room temperature at different flow rates of cooled air and different ambient temperatures. The reduction of the initial room temperature at lower ambient temperature is higher than that at higher ambient temperature. The reduction of initial room temperature is decreasing approximately linearly with the decrease of the flow rate of cooled air.

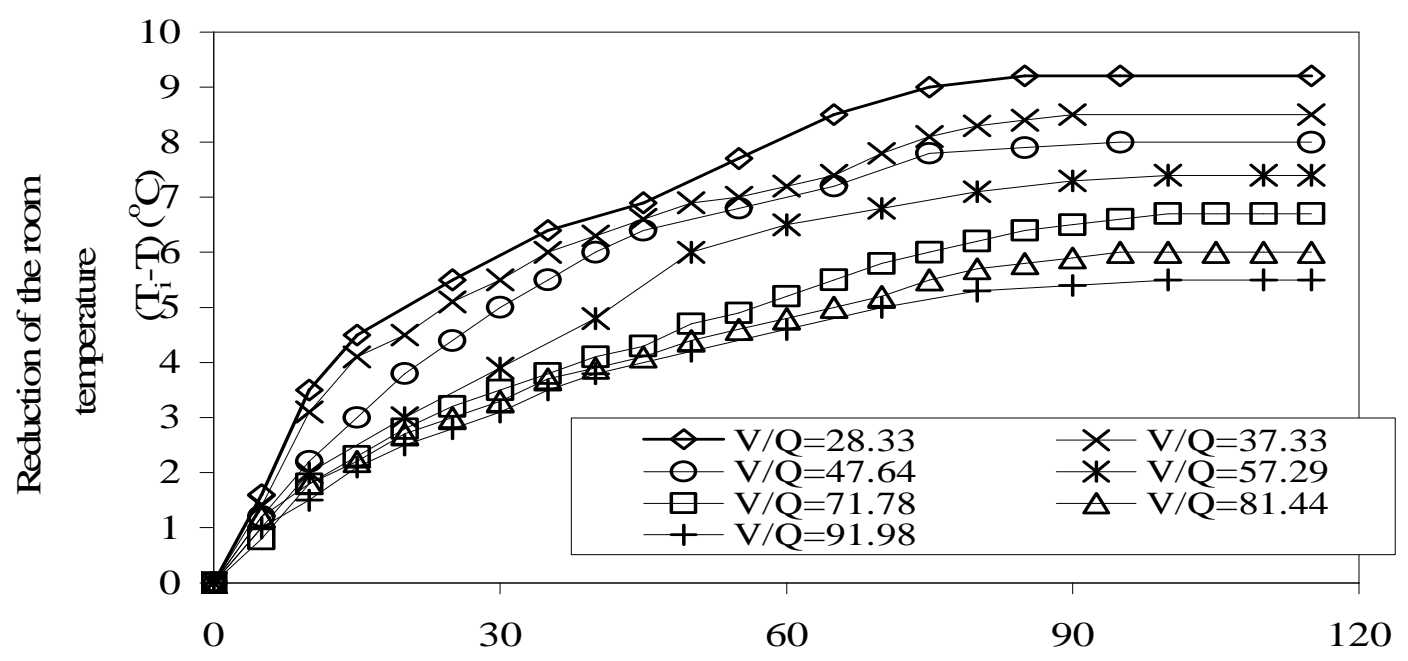

Fig. 3 Instant room temperatuffe athdifferent flow rates of cooled air $\left(\mathbf{T}_{\mathrm{a}}=36^{\circ} \mathrm{C}\right)$

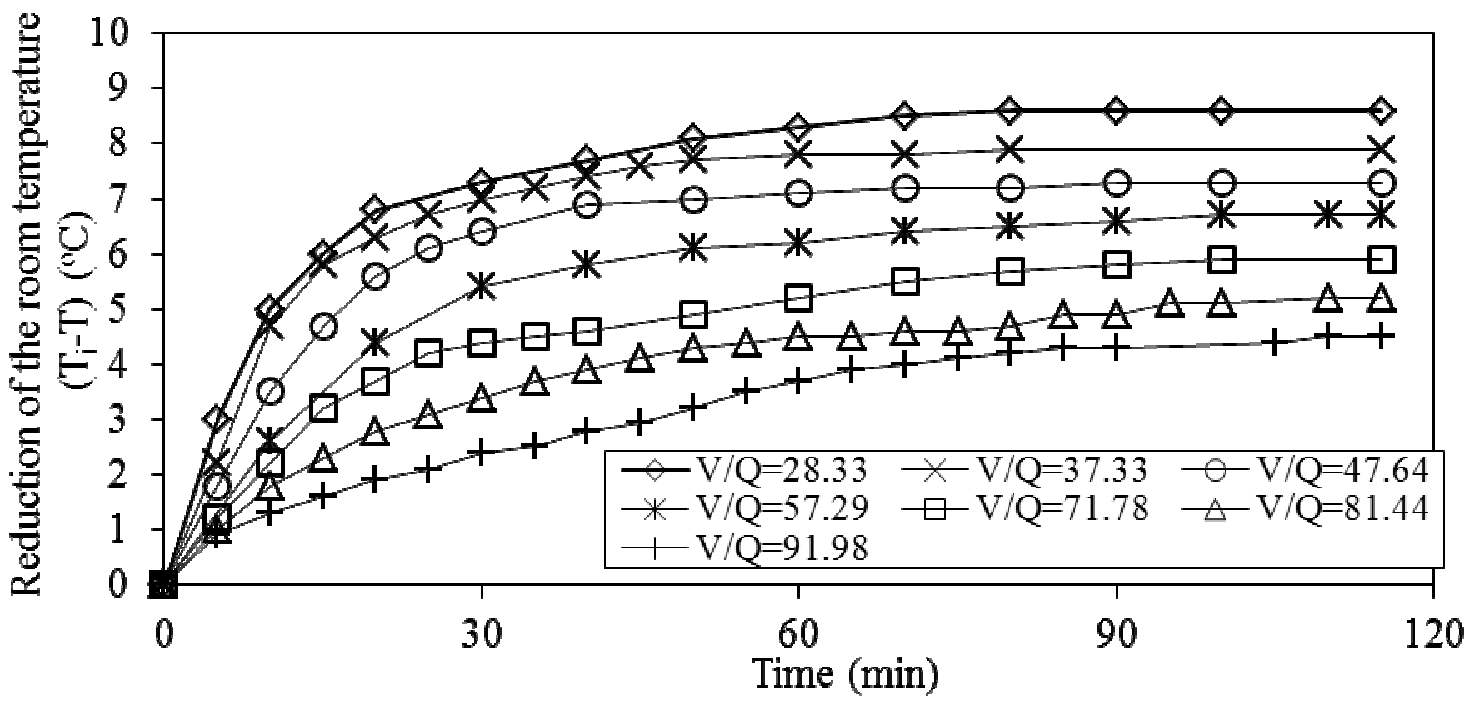

Fig. 4 Instant room temperature at different flow rates of cooled air $\left(T_{a}=42^{\circ} \mathrm{C}\right)$ 


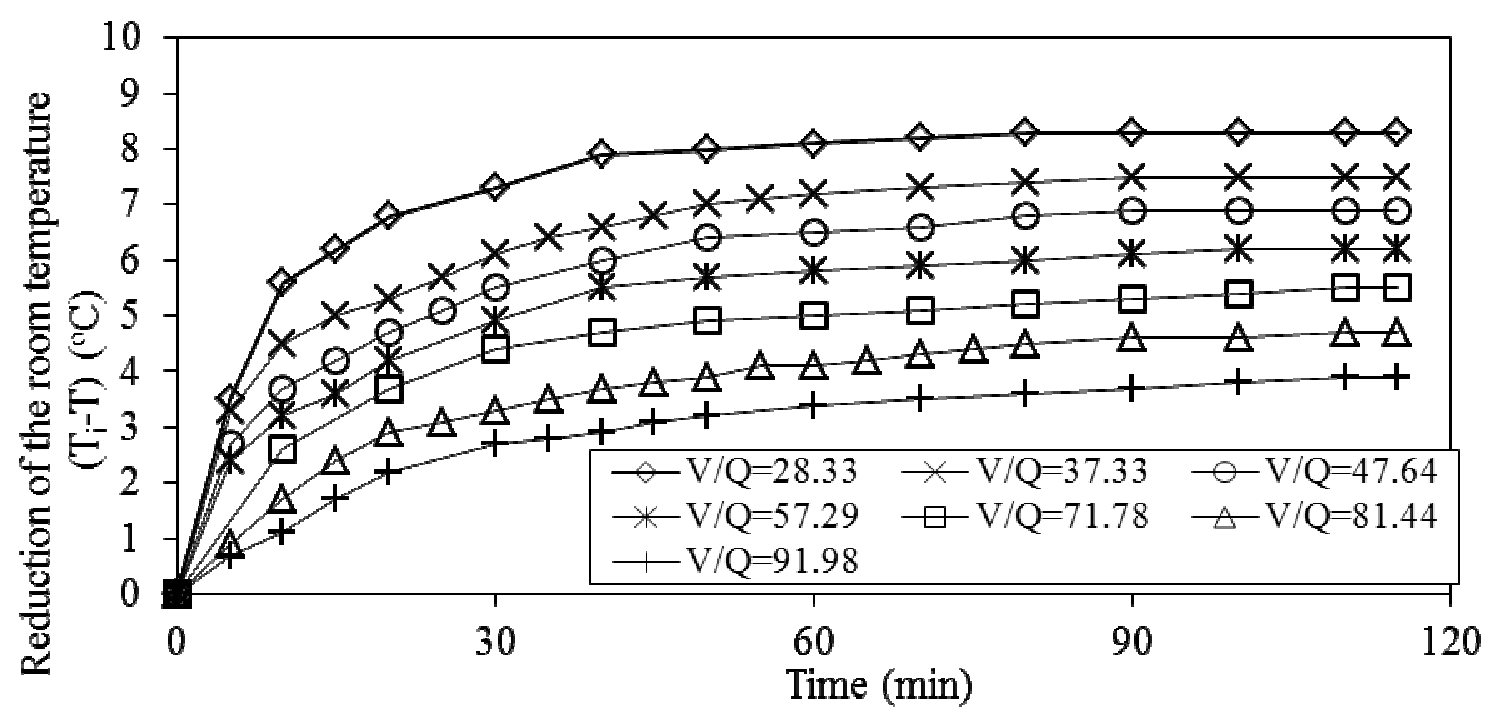

Fig. 5 Instant room temperature at different flow rates of cooled air $\left(\mathrm{T}_{\mathrm{a}}=\mathbf{4 5 ^ { \circ } \mathrm { C } )}\right.$

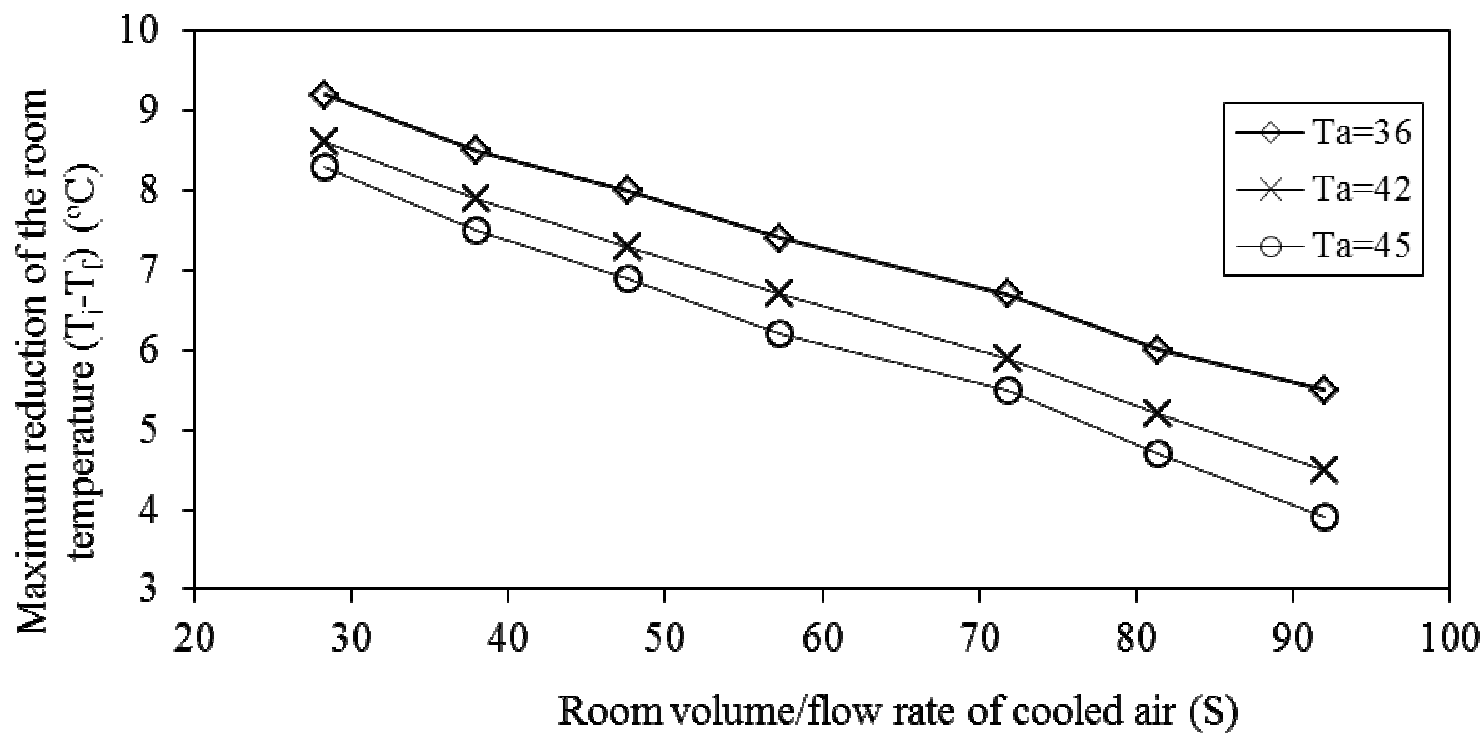

Fig. 6 Measured room temperature at different ambient temperatures

\section{MATHEMATICAL MODEL}

Prediction of the maximum reduction of the room temperature $\Delta \mathrm{T}$ due to evaporative cooler during very hot and dry climate is a considerable aim. The maximum reduction of the room temperature is a function of ambient temperature $\mathrm{T}_{\mathrm{a}}$, ambient relative humidity $\mathrm{RH}$, flow rate of cooled air $\mathrm{Q}$, room volume $\mathrm{V}$, cooler effectiveness $\varepsilon$ and heat load. 
$\Delta \mathrm{T}=\mathrm{f}\left(\mathrm{T}_{\mathrm{a}}, \mathrm{RH}, \mathrm{Q}, \mathrm{V}, \varepsilon, \mathrm{g}\right.$, heat load $)$

The ambient relative humidity is less than $20 \%$ and assumed to remain constant. The cooler effectiveness is approximately constant in the range of $75-78 \%$. The heat load is also assumed constant at the same time of the day and same climate. Therefore, the relation can be abbreviated as:

$$
\Delta \mathrm{T}=\mathrm{f}\left(\mathrm{T}_{\mathrm{a}}, \frac{g V^{5 / 3}}{Q^{2}}\right)=\mathrm{f}\left(\mathrm{T}_{\mathrm{a}}, \phi\right)
$$

Figure 7 shows that the experimental relation between the maximum reduction of the room temperature $\Delta \mathrm{T}$ and $\phi$ is approximately curve. Therefore, the parabolic equation can be assumed as:

$\Delta \mathrm{T}=\mathrm{C}_{1} \phi^{2}+\mathrm{C}_{2} \phi+\mathrm{C}_{3}$

Empirical constants $C_{1}$ and $C_{2}$ are functions of $T_{a}$ and are suggested to be expressed as:

$$
\mathrm{C}_{\mathrm{i}}=\mathrm{A}_{\mathrm{i}} \mathrm{T}_{\mathrm{a}}^{\mathrm{n}_{\mathrm{i}}}+\mathrm{B}_{\mathrm{i}}
$$

Therefore, the suggested empirical equation can be expressed as:

$$
\Delta \mathrm{T}=\left(\mathrm{A}_{1} \mathrm{~T}_{\mathrm{a}}^{\mathrm{n}_{1}}+\mathrm{B}_{1}\right) \phi^{2}+\left(\mathrm{A}_{2} \mathrm{~T}_{\mathrm{a}}^{\mathrm{n}_{2}}+\mathrm{B}_{2}\right) \phi+\left(\mathrm{A}_{3} \mathrm{~T}_{\mathrm{a}}^{\mathrm{n}_{3}}+\mathrm{B}_{3}\right)
$$

The constants $A_{i}, B_{i}$ and $n_{i}$ are determined. Substituting the constants into Eq. (6) yields the empirical equation of the maximum reduction of the room temperature, as:

$$
\Delta \mathrm{T}=\left(-1.67 \times 10^{-10} \mathrm{~T}_{\mathrm{a}}+9.5 \times 10^{-9}\right) \phi^{2}-0.0003 \phi-0.0043 \mathrm{~T}_{\mathrm{a}}^{1.7074}+11.9099
$$

Figure 7 shows a good agreement between Eq. (7) and the experimental data of the maximum reduction of the room temperature with non-dimensional group $\phi$.

Figure 8 shows the prediction of the maximum reduction of the room temperature with the flow rate of cooled air at different ambient temperatures during very dry climate.

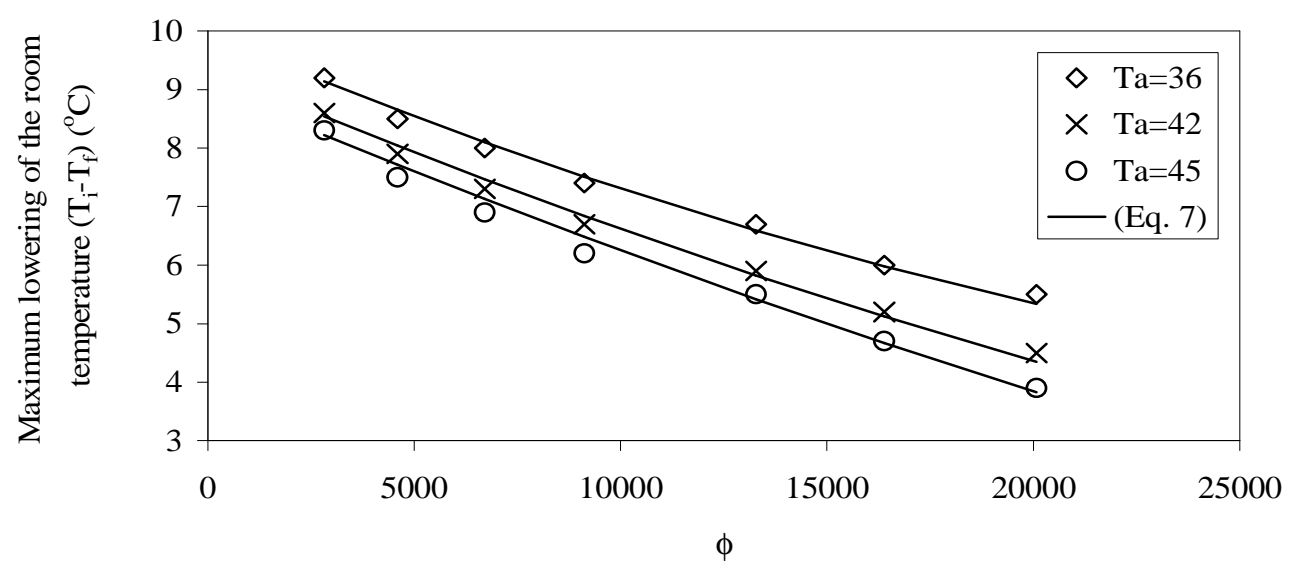

Fig. 7 Comparison between experimental and calculated room temperature at different ambient temperatures 


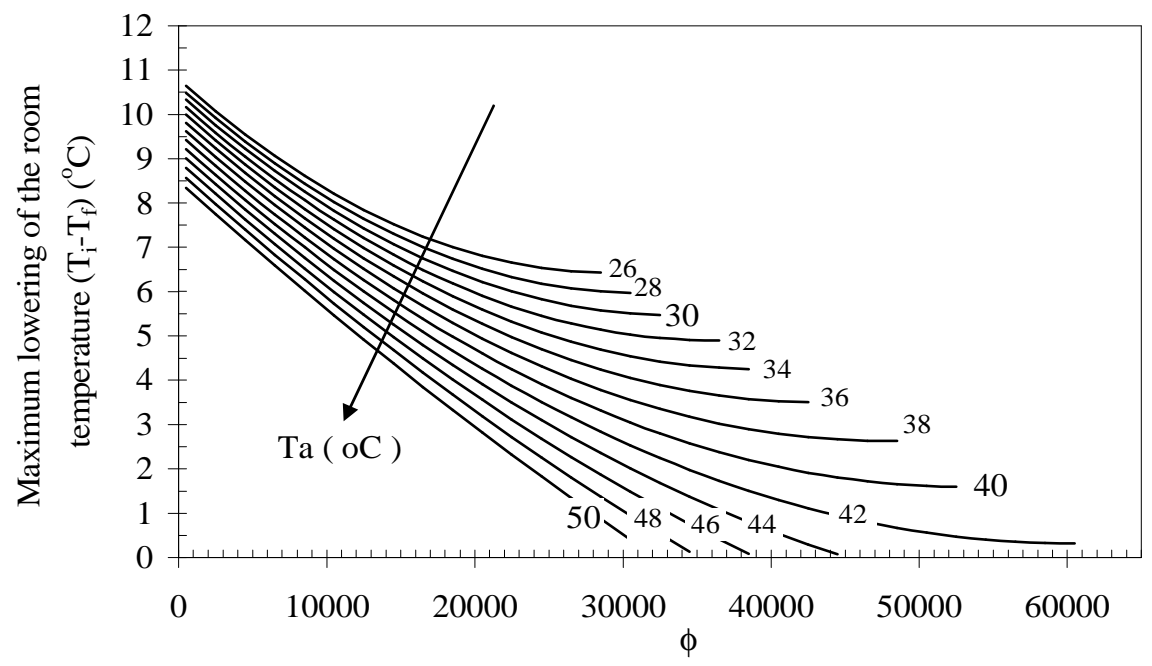

Fig. 8 Calculated room temperature at different ambient temperatures

\section{CONCLUSION}

This study succeeded to derive an empirical equation (7) capable to predict the reduction of the indoor temperature during very hot and dry climate. This prediction will be varied during another climate where the heat load, cooler effectiveness and ambient relative humidity are different.

\section{REFERENCES}

[1] Lertsatitthanakorn, C., Rerngwongwitaya, S., Soponronnarit, S., Field experiments and economic evaluation of an evaporative cooling system in a silkworm rearing house. Biosystems Engineering (2006), 93 (2), 645-658

[2] Fouda, A., Melikyan, Z., A simplified model for analysis of heat and mass transfer in a direct evaporative cooler. Applied Thermal Engineering (2011), 31, 932-936.

[3] Chen, Q., Yang, K., Wang, M., Pan, N., Guo, Z., A new approach to analysis and optimization of evaporative cooling system I: Theory. Energy (2010), 35, 24482454.

[4] Riangvilaikul, B., Kumar, S., An experimental study of a novel dew point evaporative cooling system. Energy and Buildings (2010), 42, 637-644.

[5] Wu, J.M, Huang, X., Zhang, H., Numerical investigation on the heat and mass transfer in a direct evaporative cooler. Applied Thermal Engineering (2009), 29, 195-201.

[6] Wu, J.M., Huang, X., Zhang, H., Theoretical analysis on heat and mass transfer in a direct evaporative cooler. Applied Thermal Engineering (2009), 29, 980-984.

[7] Lazzarin, R. M., Introduction of a simple diagram-based method for analyzing evaporative cooling. Applied Thermal Engineering (2007), 27, 2011-2025.

[8] Qureshi, B. A., Zubair, S. M., Comprehensive design and rating study of evaporative coolers and condensers. Part I. Performance evaluation. International Journal of Refrigeration (2006), 29, 645-658. 
[9] Qureshi, B. A., Zubair, S. M., Comprehensive design and rating study of evaporative coolers and condensers. Part II. Sensitivity analysis. International Journal of Refrigeration (2006), 29, 659-668.

[10] Camargo, J. R., Ebinuma, C. D., Silveira, J. L., Experimental performance of a direct evaporative cooler operating during summer in a Brazilian city. International Journal of Refrigeration (2005), 28, 1124-1132.

[11] Anyanwu, E.E., Design and measured performance of a porous evaporative cooler for preservation of fruits and vegetables. Energy Conversion and Management (2004), 45, 2187-2195.

[12] Kumar, K. A., Mullick, S.C., Space conditioning using evaporative cooling for summers in Delhi. Building and Environment (2001), 36, 15-25.

\section{قياس وحساب درجة حرارة الغرفة المعرضة لمبرد تبخيري خلال طقس حار جاف}

يستخدم المبرد التبخيري على نطاق واسع في المناطق ذات الطقس الحار الجاف مثل مدينة أسوان .

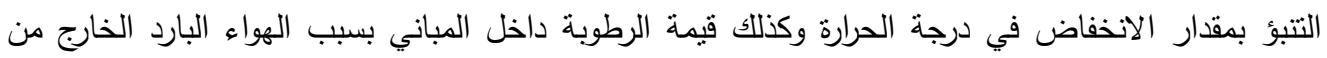

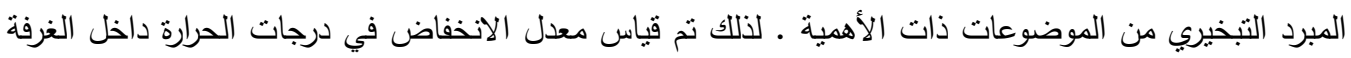

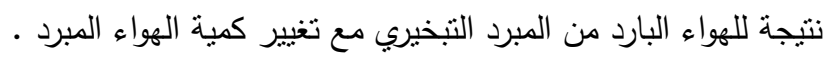

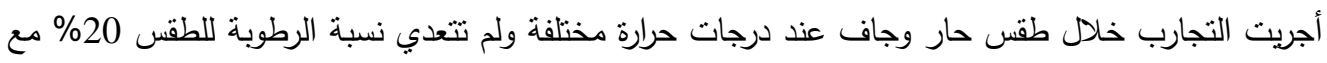

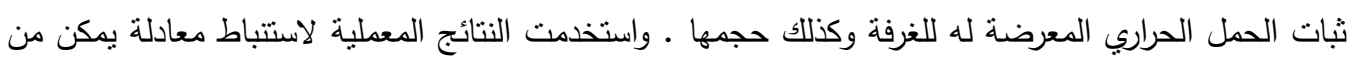
خلالها التتبؤ بمقار الانخفاض في درجة حرارة الغرفة عند ظروف مختلفة . 